\title{
Augmented Reality Navigation System on Android
}

\author{
Chee Oh Chung, Yilun He, Hoe Kyung Jung \\ Department of Computer Engineering, Paichai University, Korea
}

\begin{tabular}{|c|c|}
\hline Article Info & ABSTRACT \\
\hline Article history: & \multirow{11}{*}{$\begin{array}{l}\text { With the advent of the Android system, smart phones are rapidly developing } \\
\text { and through the conveniency of accessing internet on the smart phones, a } \\
\text { user's location information can be accessed anywhere and anytime easily. } \\
\text { Augmented Reality Based Technology enables the provision of variety } \\
\text { information such as pictures and location of buildings in the navigation field. } \\
\text { Most of the augmented reality program used to Visual Trace Method (Marker } \\
\text { method and Markerless Method). For the Visual Trace Method, the marker } \\
\text { installation and digital information should be assigned while the Non-visual } \\
\text { Trace Method requires the use of hardware (G.P.S, sensors etc). Most } \\
\text { navigation systems can only show the path from a user's current location to } \\
\text { their destination. In this paper, the design and implementation of an } \\
\text { augmented reality program is discussed. It will use the smart phone's inbuilt } \\
\text { camera and GPS to display a user's surround information in real time on the } \\
\text { smart phone. The proposed system will combine the G.P.S location-based } \\
\text { technology and virtual trace technology to provide the user with basic } \\
\text { information about a building they are looking for or one in their immediate } \\
\text { surrounding. }\end{array}$} \\
\hline Received Aug 13, 2015 & \\
\hline Revised Nov 17, 2015 & \\
\hline Accepted Dec 4, 2015 & \\
\hline Keyword: & \\
\hline Android & \\
\hline Augmented Reality & \\
\hline GPS & \\
\hline Navigation & \\
\hline POI & \\
\hline Sensor & \\
\hline
\end{tabular}

Copyright () 2016 Institute of Advanced Engineering and Science. All rights reserved.

\section{Corresponding Author:}

Hoe Kyung Jung,

Departement of Computer Engineering,

Paichai University,

155-40 University Road, Seogu, DaeJeon, Korea

Email: hkjung@pcu.ac.kr

\section{INTRODUCTION}

With the advent of the Android system, smart phones are rapidly developing and through the conveniency of accessing internet on the smart phones, a user's location information can be accessed anywhere and anytime easily. Augmented reality technology can be applied in various industries and by it promoting the formation of a new realistic media industry through its convergence with the existing industries, it is expected to be full-speed ahead in the various fields of industrial application such as advertising, education, health care, mechanical assembly, military simulation, architectural and urban planning navigation [1-3].

In particular, in order to match up the pace of the development of the data communication technology, time and space limits have been removed and also additional information can be displayed on the user's display and by clicking on a certain mark on the screen, more detailed information is displayed. The augmented reality terminal is being considered for use not only in smart phones but in portable console games, navigation systems too because they can have the camera, G.P.S, communication, display etc can be operated on them. However, the G.P.S system can display in real time a user's current location to their destination only which is a limited service. Also, the user cannot select areas or buildings that are not displayed on the screen. Due to this kind of short comings, the user has to update the navigation system which at times might require some fees to do so.

In this paper, a navigation system that uses tags to explain major facilities using surrounding information acquired through the user's smart phone, creates and adds new tags is proposed. 


\section{RELATED RESEARCH}

In this chapter, the augmented reality technology and related technology required for the design and implementation of an augmented reality based navigation system will be discussed.

\subsection{Augmented Reality}

As part of Virtual reality field, augmented reality is a system where virtual worlds are combined with virtual reality made by computer graphics. Augmented Reality is divided into two: Marker Augmented Reality and Markerless Augmented Reality. The Marker Augmented Reality augments an object by using a special marker to easily calculate its co-ordinates. Its Resource libraries include the ARtag, ARToolkit and it provides a fast and accurate way of calculating co-ordinates in the making of a real-time augmented reality system.

The Markeless Augmented Reality does not use a special marker. Instead it uses the information of the objects in the image to augment the object. This method detects the image's 3D object's corners and then uses the original form of the object as the object's augmented position [4-6].

\subsection{Android Structure}

Android is a mobile OS made on Linux Canal technology. It has variuos APIs through which application can be made using Java and X.M.L. Through these API's Android has interoperability in that the mobile device can be applied to other various devices and sensors. Compared to the conventional computers environment, mobile devices have higher mobility and portability which is an advantage, but there is the limitation of user input and the output of the result, which is a disadvantage. However, contains a mobile device has contains a camera, G.P.S, gyrosensor etc so it can use various information eg information related to a user's location, that is, the user's current location, direction and degree of inclination and send this information to the server and get other various additional information throught the APIs and display it on the user's device. Picture 1 shows the augmented reality flow in a mobile device [7].

\subsection{Data Filtering}

When displaying information on an augmented reality screen, there are basic problems/limits faced including rendering, information congestion, human factor etc. Information congestion is an information reading problem caused by the increase in the amount of virtual information. Due to this, there is a need to maintain important data and also the information filtering technic to reduce the amount of information. Information filtering's main elements include the following: user's goal, the relationship between that goal and each object, user's position etc. Rendering deletes/removes the real objects and also does real rendering too. To improve visibility, the Human Factor is used and it comprises of delay, adaptation, tiredness and eye tiredness etc.

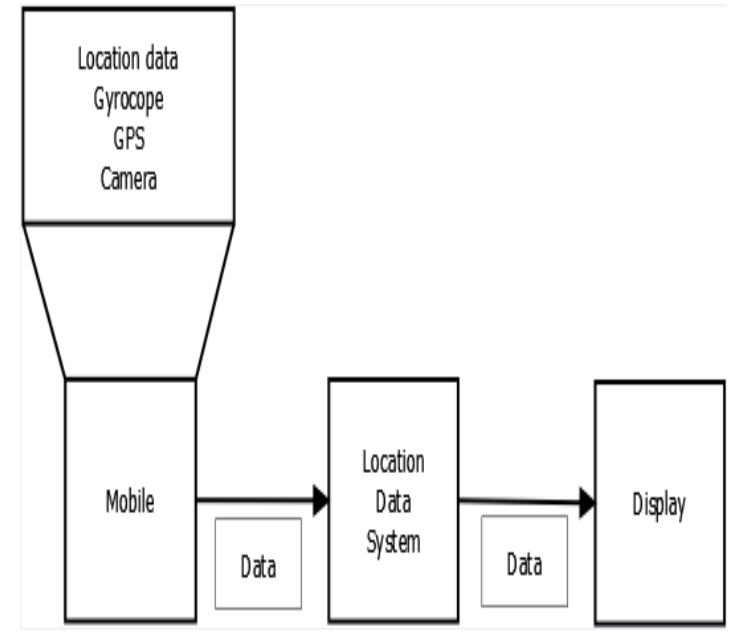

Figure 1. Mobile Device augmented reality flowchart 


\section{DESIGN AND IMPLEMENT}

In this page, the creation of an augmented reality based navigation will be discussed. Picture 2 shows the structure of the augmented reality based navigation.

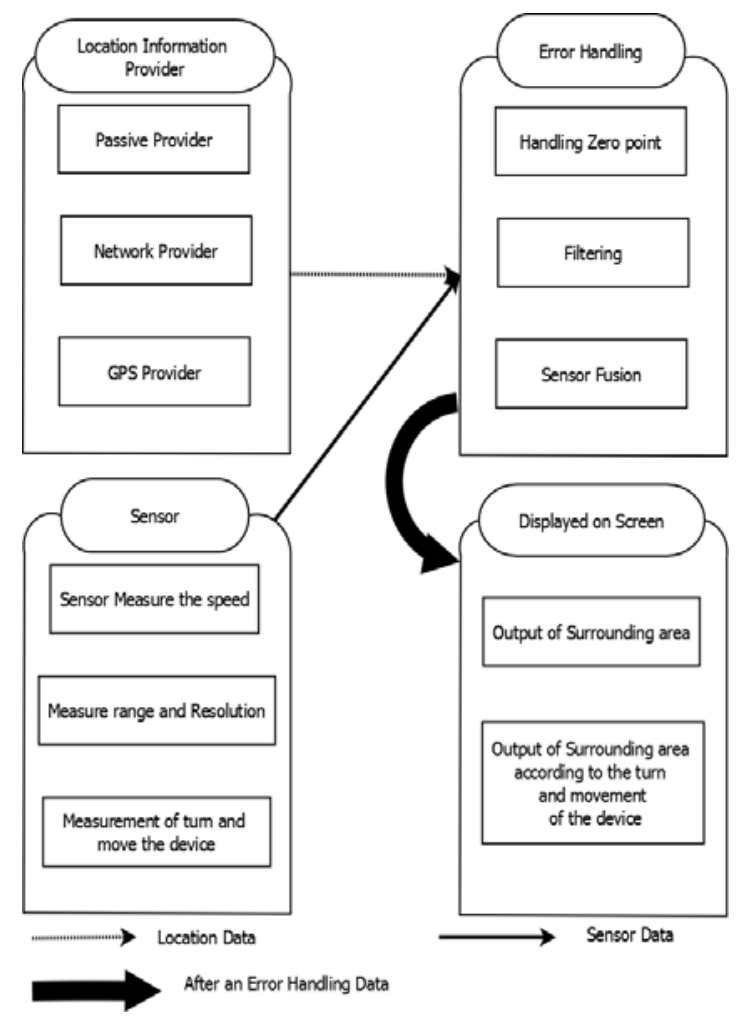

Figure 2. Augmented Reality-based Navigation System Structure

In this paper, the system consists of the following parts: location data provided by the location service provider, sensor data provided by the many sensors inside the device, the filter part that filters out the errors with the errors found in the sensor data and location data and the output processor that compares the device's resolution and movement in order for the user to be able to view the data obtained on their screen.

First, types of location service providers include passive providers, network providers and G.P.S. When choosing a location service provider one should take into consideration the accuracy level and optimization of the increasing battery consumption. In the system explained in this paper, GPS, network location provider and passive location provider are combinedly used. Graph 1 shows the comparison of each location service provider' accuracy level and battery consumption level.

Table 1. Comparison of Location Provider

\begin{tabular}{ccc}
\hline $\begin{array}{c}\text { Location Service } \\
\text { Provider }\end{array}$ & $\begin{array}{c}\text { Battery Consumption } \\
\text { Level }\end{array}$ & Accuracy Level \\
\hline GPS & High & Highest \\
Network Provider & lower than GPS & $\begin{array}{c}\text { Lower than GPS by } \\
\text { many levels } \\
\text { N/A }\end{array}$ \\
Passive provider & N/A & N \\
\hline
\end{tabular}

The information that is displayed on the system includes location data, user's location data and sensor data that track the user's movements. Since the sensors track the user's location and their movements, any events that arise are compared to the system's measured speed and are displayed. Also, rotation matrix is used to get the device's rotation and movement which is required for data about the user's movements. The technology used to detect location and movement is called tracing technology. 
Tracing technology is divided into three: sensor-based, vision-based and hybrid tracing technology. Sensor based tracing technology uses G.P.S, digital compass, acceleration sensor gyro sensor etc and detects object position and movement, speed and direction. Vision-based tracing technology can be divided into marker-based method, makerless-based methods and object detecting/image matching based method. Marker-based augmented reality uses a special marker to easily calculate co-ordinate points for use in augmenting an object. The markerless-based method augmented reality does not use a marker in order to increase the user's immersion. Instead it uses the characteristics of the objects in the image to augment the object. Hybrid tracing technology is a combination of sensor-based and vision-based tracking technology. Most mobile based augmented reality systems use the sensor-based tracking technology but with the recent development in terminal performance, the use of the marker-less based method's tracking technology is rising. Table two shows the comparison of the tracking technologies.

Table 2. Comparison of Location Provider

\begin{tabular}{|c|c|c|c|}
\hline Based & Sensor & Advantage & Weakness \\
\hline Sensor-based & $\begin{array}{c}\text { GPS } \\
\text { Gyro } \\
\text { Accelerometer }\end{array}$ & Easy to develop & $\begin{array}{l}\text { uncormfortable } \\
\text { in indoor } \\
\text { movement }\end{array}$ \\
\hline Vision-based & $\begin{array}{l}\text { Computer Vision } \\
\text { Open GL } \\
\text { Marker based } \\
\text { Marker-less based }\end{array}$ & High immersion level & $\begin{array}{c}\text { self technology } \\
\text { development }\end{array}$ \\
\hline Hybrid & Vision + Sensor & $\begin{array}{l}\text { If tracking is lost, it } \\
\text { will be compensated } \\
\text { through the sensor. } \\
\text { The weight of the } \\
\text { vision is compensated } \\
\text { by the sensor }\end{array}$ & $\begin{array}{c}\text { Hard to } \\
\text { develop, } \\
\text { Unavailability } \\
\text { of contents }\end{array}$ \\
\hline
\end{tabular}

When the system receives data from the location service provider and sensors, it needs to take care of any errors that may arise and also process the data.

The sensor's zero correction and sensor fusion are ways in which these errors can be corrected. The navigation receives a lot of location data from many location services and it has to filter the data, deciding which location data to accept and which to ignore. The location and sensor data which has had its errors eliminated are displayed on the device's screen and the POI. Also, data about the surrounding area and information brought about the device's rotation and movement is displayed, and hence the user's are able to conveniently get location data.

In this chapter, the implementation of the augmented reality navigation system is discusses. Table 3 shows the system developing environment.

Table 3. Navigation System Development Environment

\begin{tabular}{cc}
\hline Developing tool & Eclipse, Edit plus \\
\hline Language & JAVA, Android \\
Mobile Device & Android 4.4.2 \\
Galaxy S4 \\
$\begin{array}{c}\text { PC operating } \\
\text { system }\end{array}$ & Window 7 Enterprise K \\
\hline
\end{tabular}

The navigation receives a lot of location data from many location services and it has to filter the data, deciding which location data to accept and which to ignore and through this it gets accurate data. Through the aumented reality technology, the images gotten from the device's camera and POI were made to display on the screen. POI refers to the buildings and stores etc that are displayed on digital maps such as navigation.

Tools used to obtain and search POI data include Google maps, Google Earth and KML files. 'Google Earth' is different from 'Google maps' in that it uses the topography, altitude and the building's 3D model to get and search for POI data. 


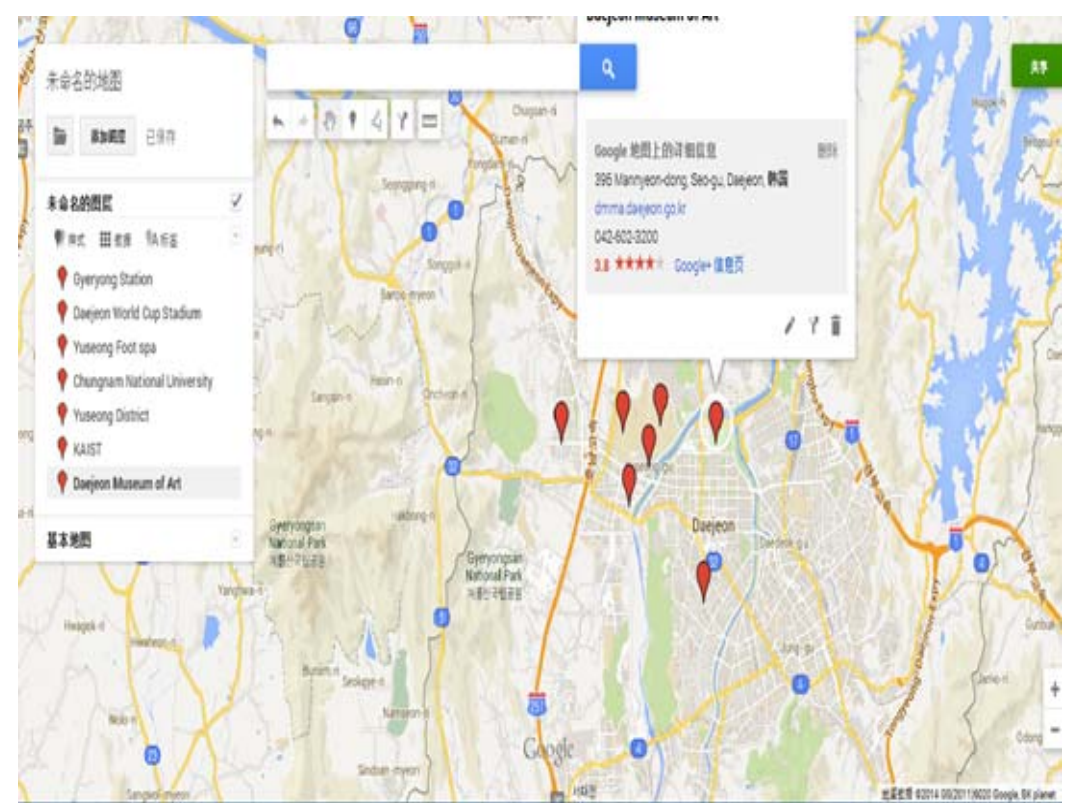

Figure 3. POI Extraction Using Google Maps

KML marks data on Earth browsers like Google Earth and Google Maps, and is used as a tag-based structure together with overlapped elements and charateristics.

This system was designed such that it takes the user's location data and the defined POI location and marks it on the radar, therefore giving a more accurate location. Also, for the locations that cannot be automatically updated, it was made possible to directly add these location by specifying the virtual POI and adding a title and the POI's data. Also, the G.P.S/ sensor were optimized so that the POI data displayed on the screen would change upon the user's movement. Picture 4 shows POI data according to the user's movement and radar display.

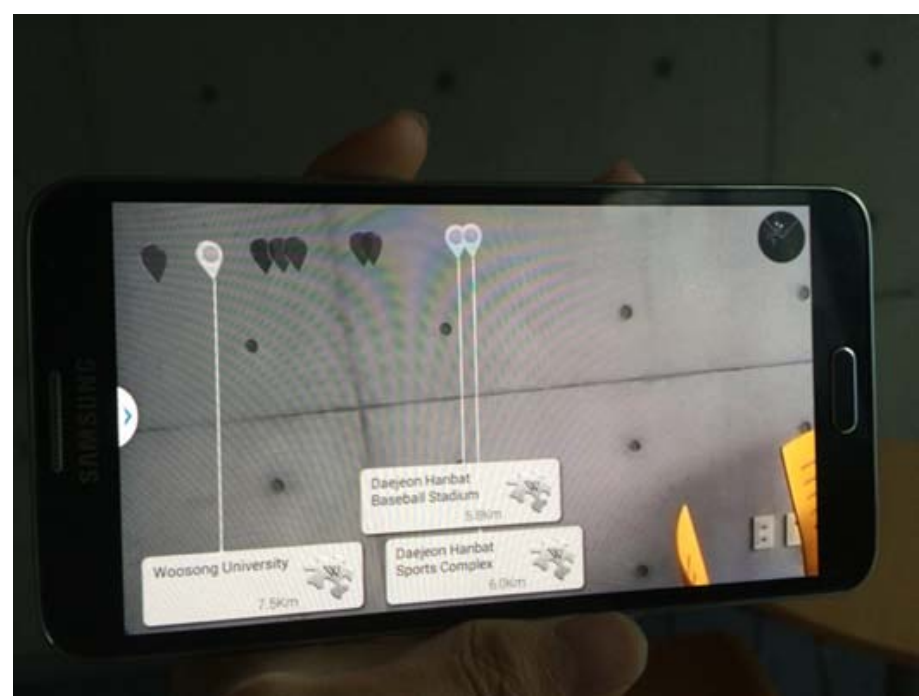

Figure 4. POI Data Screen

The POIs are displayed as spots on the screen but if the user clicks on the spots, the virtual location is displayed on a map, and a navigation showing a path is displayed. Picture 5 shows the screen display when a POI data is touched. 


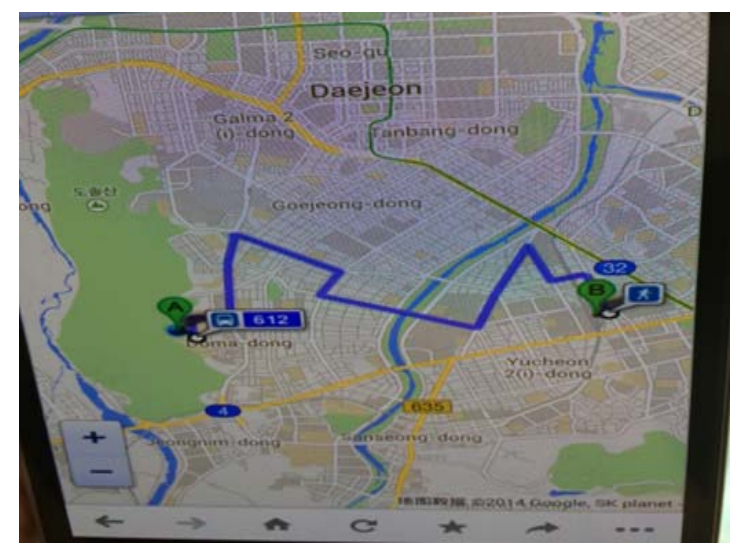

Figure 5. Touch Screen POI Data

\section{CONCLUSION}

In contrast with the current augmented reality technology, this paper has detailed analysis and research and also the testing and exploration of augmented reality technology was carried out. The existing navigation system had to get destination location information entered and only after checking the user's current location would it then show the path from the user's current location to the destination which is a limitative service. The augmented reality navigation system discussed in this paper grafts the augmented reality system's concept, characteristics, scope of application and technologies to the existing navigation system hence enabling the user to not only be able to check the path from their current location to the destination but also they can check the information about their current location's surrounding too. Among the types of augmented reality technologies, computer vision-based registration technology and reality fusion technology were researched, location data was obtained from location service providers like G.P.S and methods of how to reduce related errors was analysed and also research was done on how to accurately acquire sensor data on the smart phone.

The augmented reality-based navigation system developed in this paper is made up of the combination of virtual objects and the real world, the location data sent by location providers and sensor data gotten from sensors was combined, the navigation's system's errors were minimized and through the virtual objects, the user can be shown information about their current location's surrounding. However, future researchers need to do a lot of research on how to add POI data in real-time.

\section{REFERENCES}

[1] Carmigniani, Julie, et al. "Augmented reality technologies, systems and applications", Multimedia Tools and Applications, 51.1 pp. 341-377. 2011.

[2] Guan T, Li L, Wang C, "Using Homography to Improve the Registration Performance of ARTOOLKIT", Microelectronics \& Computer, 2007.

[3] Qin W, Zha J, Zhao Z, “Study on Artificial Mark Recognition in Augmented Reality”, Measurement \& Control Technology, 2008.

[4] Jens Grubert, Dr. Raphael Grasset, “Augmented Reality for Android Application Development”, Packt Publishing, pp. 74-75, 2013.

[5] Fritz, Jan, et al. "Augmented Reality Visualization with Use of Image Overlay Technology for MR Imaging-guided Interventions: Assessment of Performance in Cadaveric Shoulder and Hip Arthrography at 1.5 T", Radiology, pp. 254-259, 2012.

[6] Schall, Gerhard, et al. "Handheld augmented reality for underground infrastructure visualization", Personal and ubiquitous computing, 13.4 pp. 281-291. 2009.

[7] C.T. Tan, G.H. Hwang, D.K. Kang, "Game Transformation from Non-Augmented Reality to Augmented Reality”, Journal of information and communication convergence engineering, vol. 9, pp. 619-623, Oct 2011. 


\section{BIOGRAPHIES OF AUTHORS}

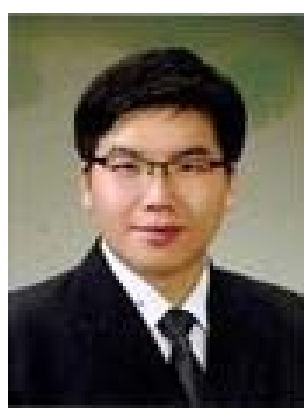

Chee Oh Chung; He received the M.S. degree in 2000 from the Department of Electronics Engineering of Kumoh National University, Korea. From 2006 to 2012, he worked for GIO as a CEO. His current research interests include The Internet of Things, information and communications technology processing, and smart manufacturing.

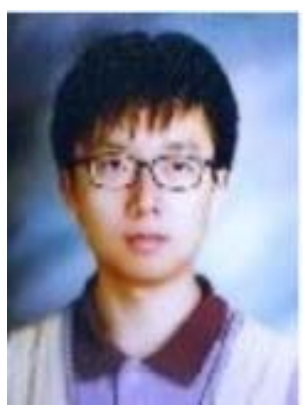

Yilun He; He received the M.S.degree in 2015 from the Department of Computer Engineering of Paichai University, Korea. His current research interests include Robot Vision, Data Mining, HTML5, WebGL, IoT, Mining the Social Web.

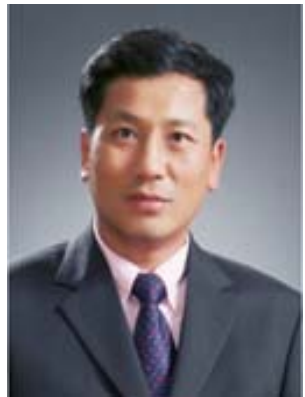

Hoe Kyung Jung; He received the M.S. degree in 1987 and Ph. D. degree in 1993 from the Department of Computer Engineering of Kwangwoon University, Korea. From 1994 to 1995, he worked for ETRI as a researcher. Since 1994, he has worked in the Department of Computer Engineering at Paichai University, where he now works as a professor. His current research interests include multimedia document architecture modeling, information processing, information retrieval, and databases. 